Article

\title{
Technological Entrepreneurship: How does Environmental Turbulence Impact upon Collaboration Risk?
}

\author{
Iwona Staniec \\ Department of Management, Lodz University of Technology, 90-924 Łódź, Poland ; iwona.staniec@p.lodz.pl; \\ Tel.: +48-693-440-916
}

Received: 30 May 2018; Accepted: 1 August 2018; Published: 5 August 2018

\begin{abstract}
The aim of this paper is to identify the impact of environmental turbulence on the risk of cooperation in technological entrepreneurship. Multidimensional factors such as the risk of cooperation, environmental turbulence, and the reaction to operationalized changes were selected during the literature review, and were subjected to empirical verification on a 304 element sample of SMEs, which are implementing technology entrepreneurship. The study used a questionnaire interview technique conducted directly in the company, and the research tool was a specially prepared questionnaire. Because of the multidimensional character of the studied variables, structural modelling was chosen. In addition, the influence of selected mediators and moderators on the relationship between the turbulence of the environment and the risk of cooperation in technological entrepreneurship was examined. The article has been divided into five main sections. The first section constitutes the introduction to the deliberations. A detailed review of the literature, taking into account the principles of operationalization of each of the presented variables, is discussed in the second section. The methodology used is then presented. In the next section of the paper, the results of the research are presented and then a broad discussion of these results is undertaken. The last section is a summary of the conducted research and its limitations. Knowledge about the antecedents of cooperation risk allows for the minimization of the presence of adverse phenomena, while knowledge of the directions of their impact greatly enriches the experience in the management of this type of relationship. The presented research may contribute to the construction of a rational model of the cooperation risk management process, in particular, in the case of adopting resources existing within the organization.
\end{abstract}

Keywords: environment turbulence; collaboration risk; technological entrepreneurship; structural modelling

\section{Introduction}

As a result of existing determinants, technological entrepreneurship constitutes an interesting research challenge in management science. This paper discusses the impact of environmental turbulence on the risk of collaboration. In the article's deliberation, Ansoff's [1] (p. 58) definition of the turbulent environment is adopted, which requires constant adaptation and on-going utilization in the conditions of Schumpeter's creative destruction [2]. Environmental turbulence is a factor determining the commitment to the processes of technology transfer and acquisition. According to the research presented in the literature [3], the unpredictability of the environment, the complexity of change, and their ever-faster pace affects the search for new ways of operation, and increases the uncertainty of collaboration. Empirical studies regarding the impact of environmental turbulence on the risk of collaboration are carried out in this paper. In this regard, the literature review is crucial, as it plays the following roles: 
- cognitive, by presenting the matters of environmental turbulence, the risk of collaboration, and reaction to change that exist within the various directions of research;

- confirmative, by identifying gaps in the existing research and testing whether the performed empirical studies have achieved satisfactory and/or contradictory results with respect to the research presented in the literature.

The following research questions are posed in the paper:

Q1. Does environmental turbulence have a significant impact on the risk of collaboration in technological entrepreneurship?

Q2. Do reactions to change mitigate the impact of environmental turbulence on the risk of collaboration in technological entrepreneurship?

Q3. What features of technological entrepreneurship moderate the impact of environmental turbulence on the risk of collaboration?

As mentioned above, the presented article consists of five sections. The first section is an introduction to the subject of technological entrepreneurship together with the posing of research questions. The second section consists of a critical analysis of the literature. The first part of the second section presents the definitions and determinants of the functioning of technological entrepreneurship. In the second part, attention is paid to the adaptive perception of the environment, which forces enterprises to actively adapt to the changes taking place in it. The third part of the second section presents the risk of cooperation and the factors shaping it. The third section describes the research methodology and the constructed theoretical model. The fourth section presents the results of the empirical research. It starts with the description of the sample, continues through the empirical model, and ends with a discussion of the results. The fifth section presents the conclusions reached from the research, further research directions, and the limitations determining the implementation of such an empirical approach.

\section{Literature Review}

This section will carry out a critical analysis of the literature in three aspects, namely, technological entrepreneurship, uncertainty of the environment and the reaction of companies to changes, and the risk of cooperation.

\subsection{Technological Entrepreneurship}

The concept of technological entrepreneurship is ambiguous, for example, Beckman et al. [4] (pp. 89-93) offer several models of this kind of business implementation. The formal establishment of technological entrepreneurship dates back to 2001, when a symposium of technology companies and research universities was organised in the USA to promote technology-based ventures. An agreement was reached that in this type of entrepreneurship, with universities being the domain of researchers, are just as important as entrepreneurs who create new activities or products and find markets for them. It is assumed that technological entrepreneurship derives from the West Coast Research Symposium (WCRS) on Technology Entrepreneurship, which is a self-organising and self-financing social cluster that has neither a formal infrastructure collaboration nor interpersonal collaboration.

The basis for technological entrepreneurship is an innovative idea or a technological solution leading to the creation of a new or improved product. Such a product can be, for example, a new machine, a small element of a product, an IT solution (e.g., a portal), a system, or a mathematical algorithm offering practical applications. It is important that this solution brings new quality in relation to the solutions applied so far. The source of the created solution is the scientific knowledge of the creators and the representatives of the universities or research centres. Technological entrepreneurship refers directly to technical aspects, previously unknown methods of production, the provision of services, the creation of new products, services and systems, the innovative organisation of processes, 
and other types of activities that are based on the use of knowledge and/or collaboration with scientific and research centres.

Technological entrepreneurship stems from mainstream entrepreneurship by focusing on the possibilities of supporting innovations in science and engineering. It mainly concerns the introduction of technical innovations to emerging markets, and new products that enable this introduction. Research in the area of technological entrepreneurship is the interconnection of disciplines, entrepreneurship, and technological innovation. Management theories, such as entrepreneurship theory, innovation theory, and determinants of the high technology sector, are components of technological entrepreneurship and boast well-established research achievements [4] (pp. 89-93). Technological entrepreneurship links entrepreneurship-as a domain of social sciences-with technical sciences, because it owes its development to technological advances (e.g., in IT and telecommunications technologies, biotechnology, nanotechnology, etc.). The research direction in technological entrepreneurship stems from the statement made by Baumol [5] (p. 606), that the study of business cannot function without paying attention to the phenomenon of entrepreneurship, for example, who launches it, and when, where, why, and how they evolve (or not) over time.

As a result of the nature of technological entrepreneurship and the commercialisation of scientific research outcomes, the close collaboration of technological entrepreneurship with broadly understood research and scientific milieus (e.g., universities, research and development units, centres supporting small and medium enterprises, technology transfer centres, etc.) is indispensable [6].

What follows from these considerations is that the phenomenon of technological entrepreneurship occurs when the development of science and technology creates a key element of an entrepreneurial opportunity, enabling the generation of a given undertaking. Thus, the typical features of technological entrepreneurship are as follows:

\section{- anticipation of technological changes;}

- management of external and internal relations; and

- the method of organising resources and their externalisation that would facilitate development through the exploitation of the emerging technological opportunity.

Beckman et al. [4] ( p. 89) show that technological entrepreneurship makes use of an element of opportunity that is based on the effects of network advantages, technical standards, and cost reduction. Ferreira et al. [7], on the basis of a categorized bibliometric analysis (135 articles published in the years 1986-2013), present the existing knowledge on technological entrepreneurship. They emphasize that technological entrepreneurship consists of creating new options by reorganizing and transforming existing resources. They also show that in technological entrepreneurship, in addition to the characteristic features of the entrepreneur, it is necessary to take into account the characteristics of the environment and the requirements of the market itself, which may favour (or inhibit) the development of this type of entrepreneurship.

Harms and Walsh [8], stress the importance of material resources, such as financial resources, as well as intangible opportunities, such as procedures and experience. In this type of activity, the technology itself is key and can be a link between the cognitive aspect of technological change and the cognitive perspective in entrepreneurship.

Antoncic and Prodan [9] show that corporate entrepreneurship can be considered as an important factor for organizational efficiency. The model they created indicates the value of involvement in strategic alliances for the development of enterprises' activities in the field of technological entrepreneurship and the resulting improvement in efficiency (the model has been tested by means of 226 useful responses from data from postal surveys taken from a sample of manufacturing companies in Slovenia).

In this work, it was assumed that technological entrepreneurship covers all projects implemented by companies from the SME sector that are related to the transformation of the research results and 
research potential of research institutions, as well as the research potential of scientific institutions, enterprises, and independent producers into goods and services.

Most researchers confirm that the size of the company, its relations with stakeholders, and its financial situation determine the steps taken by the company, regarding both the present and the future. These considerations enabled the formulation of the following research hypothesis:

Hypothesis 1 (H1). Features describing specifics such as company size, financial situation, and relations created with stakeholders, impact upon the functioning and appropriate responses in technological entrepreneurship.

\subsection{Environment Turbulence and Reaction to Change}

The concept of ambient turbulence was introduced by Ansoff [1] (p. 58), defining it by means of the characteristics of the degree of growth of its novelty, complexity, and intensity, as well as by the speed of change occurring within it. According to Ansoff [1], the turbulence of a company's environment constantly intensifies. He distinguishes four basic trends that define it, namely:

- increase in the change of novelty, which means that important events at the company deviate more and more from employee experience;

- increase in environmental intensity, which means that the recognition and maintenance of the relationship between the company and its partners requires the intensification of both resource commitment and management attention;

- increase in the speed of change in the environment, which means that changes are fast and occur frequently, so the company must constantly adapt to such changing conditions; and

- increase in the complexity of the environment, which means that events are becoming less and less predictable.

Frishammar [10] (p. 41) emphasizes that when the environment affects the functioning of a company, the company adopts an adaptive attitude, that is, it adapts to the changes taking place. Kotler and Castoline [11] (pp. 83-85) claim that the current environment is characterised by fluctuations and dynamic changes, which cannot be forecast, increasing risk and uncertainty in the operation of any organisation. Whereas Sull [12] (p. 20) asserts that turbulence is a measure of the frequency of unforeseeable changes that affect the ability of enterprises to create and maintain a value. Erlogu and Hofer [13] consider the environment to be turbulent because it is characterised by unpredictability.

Dess and Beard [14] stress that a turbulent environment can be described by frequent turbulent, non-linear changes, which are therefore difficult to predict. Changes in the turbulent environment are becoming increasingly similar to chaotic systems, which means that both the nature of change and their effects are difficult to predict.

Lawrence and Lorsch [15] show that organizations must adapt to external change in order to survive in this rapidly changing world. While the internal, rational decisions within firms do somewhat determine an organization's goals and strategies, their success is ultimately measured by their survival and their ability to cope with the environment.

Schneider, Wickert, and Marti [16] state that the type of environment is related to the number of elements being considered at the same time, their individual diversity, and the identification of their mutual connections In their work, Volberd and van Bruggen [17] emphasize that the contemporary environment is characterized firstly by the dynamism of changes that are identified on the basis of their intensity and frequency; secondly, by complexity, which is understood as the number and degree of interrelatedness of environmental elements; and thirdly, by predictability (i.e., the availability of information and its future verifiability). At the same time, they emphasize that the first two conditions are crucial. Manu [18] emphasize that a desirable feature of companies operating in a turbulent environment is reducing the reaction time to change and increasing flexibility.

Summing up, it should be noted that an important determinant of environment turbulence, to which everyone pays attention, consists of Ansoff's [1] (p. 58) four tendencies regarding change taking 
place. These tendencies are also adopted in further studies, including Volberd and van Bruggen [17]; Erlogu and Hofer [13]; and Schneider, Wickert, and Martin [16]. According to this approach, the environment affects the operation of technological entrepreneurship. On the one hand, it is a source of threats, and on the other hand, it provides the chance to seize an emerging opportunity.

The presented considerations emphasize the fact that the turbulence of the environment is measured and defined differently, but significantly affects the decisions taken by the companies, even though it is measured and defined in various ways.

The perception of the environment affects the organisation's response and its approach to emerging changes. The company adapts to the environment through appropriate responses to such emerging changes. The following approaches are popular in the literature [16]:

- diagnostic - based on a critical analysis of the actual state and striving for the most favourable solution;

- forecasting - prediction of an ideal solution based on the latest scientific achievements while incorporating a feasibility option; and

- diagnostic and forecasting - the ideal solution is a synthesis, an analysis of the actual state is carried out, a technical feasibility is assigned to the model, and a dynamic adjustment to the situation takes place.

There is also an approach [18] (p. 123) that treats the changeability of the environment as a constant, and considers the business to be a variable that ensures the flexibility of the company.

In addition, the adaptive ability, highlighted by Frishammar [10], highlights the important role of the approach of the change in the companies' response to change. Swiatowiec-Szczepańska [19] and Fudaliński [20] emphasize that the process of selecting the company's goals and strategies (i.e., their reaction to changes in the environment) determines the risk of strategic choices. Thus, the described reaction to change is perceived in the literature as a mediator of the influence of ambient turbulence on the decisions made. These considerations allow us to formulate another hypothesis, as follows:

Hypothesis 2 (H2). The impact of the turbulence of the environment on decision-making is mediated by the organization's approach to change.

\subsection{Risk of Collaboration}

As a result of the nature of technological entrepreneurship, its close relationship with broadly understood suppliers and/or recipients of technology is indispensable. Such collaboration, from the perspective of the literature, may take various forms and models [21] (pp. 142-147), [22] (p. 20). These relationships are defined as rather reluctant, only indispensable, good neighbourly, close (in which continuous collaboration takes place), and partner-like. In empirical studies, they are grouped into two categories, namely:

- only necessary, covering: none, rather reluctant, only indispensable; and

- close, including: good neighbourly, close (in which continuous collaboration takes place), and partner-like.

These entities run operations in collaboration because of the possibilities of mutual learning or knowledge sharing [23] (p. 5). Establishing collaboration is conditioned by the selection of partners and the appropriate scope of collaboration. When looking for partners, technology enterprises use personal connections, limiting themselves to local contacts. The decision to cooperate is influenced by the experience and attitudes of management, as well as by trust in partners. The results of company collaboration affect its innovativeness [24,25] and competitiveness [26]. In the case of technological entrepreneurship, both the transfer of technology taking place in the course of collaboration with other economic or scientific units and the associated risk are of crucial importance. Short et al. [27] demonstrate the critical role of the category of time in the process of transforming opportunities into new values. Thus, when exploring a technological opportunity, there is an interaction between the 
company's operation and the changes taking place in its environment. These are the so-called recursive interactions that allow the shaping of entrepreneurial abilities as a response to external influences. Their results are the dynamic abilities to effectively conduct technological entrepreneurship, from the phase of exploration of the technological opportunity, through its conceptualisation, to the exploitation phase leading to the implementation of a technological innovation.

The study by Nooteboom, Berger, and Noorderhaven [28] tested the effects of governance and trust on the risk perceived by agents of firms in alliances. Fudalinski [20] emphasizes that the problem of change in the environment as well as the related belief that there is no real possibility to predict future conditions in order to adjust the organization, has a significant impact on the risk of collaboration. Additionally, he emphasizes that the risk management process is a dynamic phenomenon and requires constant work, correlated with the diagnosis of change in both the internal and general scale. Risk management procedures reinforce the organization's experience through a standardized description of threats or opportunities that have materialized.

Studies by Dodgson and Hinz [29] (p. 5) with regards to the increase in the importance of horizontal collaboration, show that the impact of competition, spatial proximity, quality, and the effectiveness of innovation is uncertain. Porter [23] (p. 225), in his deliberations on the competitive advantage, noted that many states in the USA and regions in Europe focused their policies on the promotion of collaboration between enterprises. He confirms, after Belussi [30] (p. 23), that trust enhances the mutual benefit resulting from relationships between enterprises and it is stronger in geographically concentrated networks than in the case of dispersed relations. The condition facilitating the absorption of knowledge generated outside the region to stimulate technological entrepreneurship within it consists of horizontal local networks significantly connected with the external world, as concentration on local connections leads to the deterioration of the competitive position of enterprises [31] (p. 298). The research by Fritsch [31], and Fritsch and Franke [32], conducted in the regions of Vienna and Slovenia, show that "collaboration is beneficial for innovation." Beckman et al. [4] (pp. 90-93) emphasize that the sources of companies' predominance on the market depend on the results of collaboration with the environment; the risk of changes in technology, which risk contributes to cost reduction; the reduction of uncertainty; and the increase in trust, especially in the case of systematic and long-lasting collaboration. Collaboration and technology transfer have a synergistic effect on the activity of technological entrepreneurship [33]. The literature also includes studies on the risk of relationships. Światowiec-Szczepańska [19] (pp. 243-277) conducted a risk assessment of a strategic partnership. The empirical research on 215 entities shows that the following hidden variables have a significant impact on the results of strategic partnership: relational standards, relational risk, contract complexity, a partner's competences, good will, and economic risk.

Yoon C., Lee K., Yoon B., and Toulan O. [34] divide the collaboration success factors into the planning process and the collaboration process. The success factors in the planning process are collaboration R\&D, methods of work and performance distribution, and geographical similarity. The success factors in the collaboration process can be divided into mutual trust and partner characteristics. There are four types of dependent variables to identify in collaboration performance, namely: financial performance, process innovation, improving competitiveness, and technology acquisition. As a result of the analysis, important success factors vary according to collaboration type, and the success factors that affect performance differ depending on the achievement type.

To summarise, based on the literature review, the risk of collaboration in technological entrepreneurship is determined by, among others, the following:

- the formalisation of collaboration [33];

- trust in a partner or experience in collaboration [28,30,35];

- flexibility of parties [31]; and

- risk awareness [19]. 
Fudalinski [20] shows, in his considerations, that the antecedent of the risk of collaboration is environmental turbulence. Diversity in the context of the risks of cooperation has enabled the formulation of a research hypothesis, namely:

Hypothesis 3 (H3). Awareness of environmental turbulence positively affects the perception of the risk of collaboration.

\section{Methodology}

The first part describes the theoretical model. In order to indicate the effect of environmental turbulence on the risk of collaboration in technological entrepreneurship, structural modelling is relied on. In the literature, the modelling of structural equations in the study of relationships has been used in many studies, including the following:

- Anderson and Narus [36] present a survey examining satisfaction with a producer-distributor relationship in the electronics sector;

- Morgan and Hunt [37] study a producer-dealer relationship in the automobile tire sector;

- Lush and Brown [38] investigate cross-sector supplier-distributor relationships;

- Carson, Madhok and Wu [39] conduct a study of cross-sectorial relationships in a group of selected enterprises;

- Rašković and MöRec [40] present a study of relationships with suppliers in international companies; and

- Rezazadeh and Nobari [41] present a conceptual model that they verify empirically indicating that the strengthening of partners' entrepreneurship is the main incentive for collaboration.

Because of the multifaceted and multidimensional nature of the problem in question, a decision has been made to use latent constructs. Individual constructs and the observable variables used to identify them are created based on evidence from the literature and by merging the results provided by different researchers, and also through the development of the model presented in the paper by Anderson, Christ, and Sedatole [42]. The proposed theoretical model, which identifies the impact of environmental turbulence on the risk of collaboration in technological entrepreneurship, is presented in Figure 1. The description of individual constructs and items that create them are presented in Table 2.

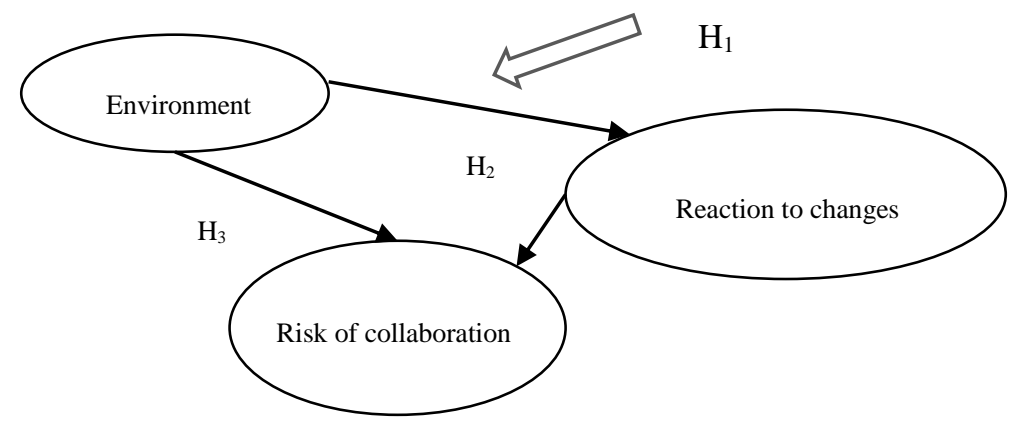

Figure 1. Theoretical model of the impact of environmental turbulence on the risk of collaboration in technological entrepreneurship.

The models of the structural equations are estimated using the maximum likelihood estimation, assuming the multidimensional normal distribution. Westland [43] shows that the requirements for the sample size and for its distribution when using structural models are most often unsatisfied. Structural models have both proponents and opponents [44]. The clear advantage of the used tool is the ability to test both the indirect and direct effects, and to introduce latent variables [45] (p. 77), [46-48]. 
As part of the presentation of the results, the causal relationships between variables are expressed using a standardized path coefficient (variance equal to one), which indicates how much the effect changes if the cause factor changes by one unit. Thus, the coefficient values describe the direction (negative/positive) and the force of the impact of the cause on the effect. There are many approaches and indicators in the literature that allow one to verify the fit of the structural model. Table 1 presents commonly used goodness of fit tests.

Table 1. Goodness of fit tests in the assessment of structural equation models.

\begin{tabular}{|c|c|}
\hline Parameter & Values and Requirements \\
\hline Statistic $\lambda 2$ and its significance $[46,49]$ & $\begin{array}{l}\text { H0: no discrepancy between the observed covariance } \\
\text { matrix and the one implied by the model. } p>0.05 \text { means } \\
\text { that the restrictions imposed by the researcher in the } \\
\text { theoretical model are correct. The usefulness of this test is } \\
\text { limited because it leads to the rejection of real models too } \\
\text { easily. It is very rarely used in empirical research to } \\
\text { verify the reliability and validity of the model. }\end{array}$ \\
\hline Quotient $\lambda 2$ by the number of degrees of freedom [50] & $\begin{array}{l}<1 \text { - too good a fit; } \\
(1 ; 5) \text { - acceptable model (some claim that the upper } \\
\text { boundary is 2); and } \\
>5 \text { - unacceptable models. }\end{array}$ \\
\hline
\end{tabular}

Steiger-Lind test ranks high among experts. This is a measure of how poorly the model fit is, taking into account its parameters that require estimation. The closer to 0 the result is, the better the theoretical model fits the

RMSEA root mean square of approximation error [51,52] matrix of results. The following is assumed for the values: $<0.01$ - perfect fit; (0.01-0.05)—good fit; (0.05-0.08)—satisfactory fit; $(0.08-0.10)$ - poor fit; and $>0.1$ indicates a bad model fit.

GFI-(Goodness of Fit)(CFI-Comparative Fit Index and IFI-Incremental Fit Index) index or AGFI- (Adjusted Goodness of Fit) indices of goodness (quality) of fit $[46,53]$

These measure the size of the variance-covariance matrix that is predicted by the reconstructed matrix. A value above 0.9 means an acceptable model; 0.95 means a satisfying one; and 1 means a perfect model fit.

Source: proprietary study, based on $[20,46,49,54,55]$.

What is important, from the analytical point of view, is the determination of the reliability of the data and the consistency of observable variables within the latent variables. To ensure those factors, the following is established: Joreskog's Rho as composite reliability (CR), average variance extracted (AVE), and Cronbach's alpha coefficient. The high reliability of the scale is indicated by values greater than 0.7 for the Cronbach's alpha coefficient, this condition is called Nunnally's criterion [56]; CR $>0.7$; and AVE $>0.5$ [55]. It is also expected that the correlations of individual variables with the summary result of the scale are higher than 0.4 [57].

Moreover, the phenomenon of moderation and mediation is introduced in order to test the acceptability of the cause and effect relationship hypothesis in the context of the characteristics of the company. It is worth emphasizing that testing the role of a moderator consists of accepting the similarity of structural weights. With the use of the effects of moderation or mediation [58] (pp. 1-22), a deeper analysis of the cause and effect is possible. This section may be divided by subheadings. It should provide a concise and precise description of the experimental results, their interpretation, and the experimental conclusions that can be drawn.

The data obtained as a result of the conducted research procedure have been analysed using the following software: Excel, AMOS, and IBM SPSS Statistics 20. During the research, the models of the structural equations performed verification and descriptive functions [53]. 
To test the model and its hypothetical relationships between constructs, a structured and standardized questionnaire was created to operationalize hidden constructs, based on scales identified in the literature. Included in the questionnaire for the measurement of the analysed constructs are four statements for environmental turbulence [1] (p. 58), three for reactions to change, and four for the risk of cooperation. The five-point Likert scale was used to measure the identified items. The questionnaire additionally contained a metric concerning size, organizational form, years of activity, capital and ownership links, financial results in the last period, and 20 questions used in the implemented project. The pre-prepared questionnaire was verified in pilot studies carried out by the authors themselves. This stage of the analysis included interviews with senior management and was aimed at verifying the clarity of statements made, as well as the exclusion of misunderstanding and possible uncertainties. Another one conducted by a research company was aimed at confirming the validity and reliability of the proposed scales based on statistical analysis using the collected data.

Conducting proper research was commissioned to a research company and to this end the computer assisted telephone (CATI) technique was used, unless it was the respondent's wish to have a direct interview with him in the company. Concerning the conducting of a telephone interview, the disadvantages of this method are the necessity of having a short questionnaire, as well as uncomplicated and simple questions. Undoubted advantages are the constant monitoring of the research, the good quality of collected data, the standardization of the collected data, the short time of data collection, and the low costs. The advantages of this technique include minimizing the risk of errors related to the lack of respondents' answers, measurement, and technique.

In this type of research, the problem is always how large should the sample be? Of course, the bigger the better. Aaker and Bogozzi [49] show that when analysing two to three subgroups, a minimum number of 200 is sufficient.

\section{Data, Empirical Results, and Discussion}

\subsection{Data}

In order to answer the research questions formulated herein, the research firm used the data collected during the research performed by the staff of the Faculty of Management at the Lodz University of Technology, in the period 2014-2017. The empirical research was performed on a randomly selected sample of 304 items. The sample was drawn by a research company, based on a purchased database of SME entities, as per their PKD (Polish Classification of Activities ) codes [B, C, $\mathrm{D}, \mathrm{H}, \mathrm{I}, \mathrm{J}]$ ). The subject of the research comprised small- and medium-sized enterprises, from which business activity utilized technical solutions arisen from their own research and development work, or which used solutions developed by other entities (universities and scientific institutes, research and development units, etc.), or based upon the ideas of natural persons. We conducted structured interviews in 304 companies, to which verification questions were posed. The survey was carried out between October and December 2017. It concerned only Polish companies, but those in all industries. As a result of the validation, none of the questionnaires were rejected and no data was missing in any of them. This was the result of sensitizing interviewers to the need to get answers and persuading the respondents that there are no bad and good answers. Anonymity was also guaranteed [15]. Using a questionnaire based on respondents' assessments is always subject to the error of subjectivism. However, in this case, the selection of respondents in the form of the persons responsible for cooperation with the technology provider allows one to suppose that the opinions expressed above correspond to the situation of the company. In addition, the research was carried out once at a given point in time, and cooperation is a long-term process. In light of the justifications presented, research limitations and potential errors should not affect the quality of the data obtained.

The research company used its internal databases effectively, around every 14th record call ended with an interview. There were 4200 companies that were drawn, and thus the rate of return in the research is around $7.14 \%$. Amongst respondents, PCA C dominated, and thus industrial companies 
constituted $67.8 \%$ of the respondents, just as in the register of Polish companies. The percentage share of the surveyed companies in the selected sections of the Polish Classification of Activities reflects the situation in the Polish market. On average, the interview took about $30 \mathrm{~min}$. The surveyed companies were dominated by limited liability companies, accounting for $52.3 \%$ of the respondents, while natural persons conducting economic activity constituted $27.6 \%$ of the respondents. In addition, these were companies operating for over five years on the market; $13.5 \%$ of the companies were functioning for over five but less than 10 years, and the companies operating over 10 years dominated-they accounted for $81.9 \%$. Of the surveyed companies, $68.1 \%$ had no capital linkages with other researched companies.

The research examining the impact of environmental turbulence on the risk of collaboration in technological entrepreneurship was carried out in 304 companies from the SME sector, that was used in their business new technical solutions, resulting from their own research and development work or from solutions developed by other entities. In most cases, these are small companies employing up to 49 people, $76 \%$ (231 entities), and medium-sized companies employing 50 to 249 people, $24 \%$ (73 entities). The entities that made a profit in 2016 comprised $75.7 \%$ (230 entities), while those that made a loss amounted to $24.3 \%$ (74 entities). This research includes a description of the type of collaboration relationships from the point of view of the company's business. The respondents describe these relationships as follows:

- $\quad 32.89 \%$ (in 100 surveyed companies) only necessary, covering: none, rather reluctant, only indispensable, or necessary; and

- $\quad 67.11 \%$ (in 204 surveyed companies) close, covering: good neighbourly, close, or even partner-like.

\subsection{Creation of Latent Variables}

Based on the empirical data (304 observation), it is verified whether the accuracy of the measurement of each of the hidden variables, measured with Cronbach's alpha, assumes a value of at least 0.7 (CR and AVE are also calculated for each variable). The detailed data is presented in Table 2 . The presented statistics show that latent variable environmental turbulence is built with all of the observable variables proposed by Ansoff [1]. The latent variable reaction to change is built with only two observable variables, because the assessment of the statement that the company needs time to react to changes in the environment is not correlated with the other statements. The weakness of these deliberations is the failure to meet the threshold conditions by the constructed risk or collaboration and the observable variables that represent it.

A construct defined as the risk of collaboration does not reach the threshold values of the analysed indicators, despite the rejection of the variable formalisation of the collaboration (i.e., we suspect that the scale is only marginally reliable, but under certain conditions it may be acceptable). The determined factor loads are higher than 0.7 , which means that this construct is acceptable.

The reliability of measurement for the risk of cooperation determined by means of Cronbach's alpha is 0.659 , and CR is 0.693 , AVE [59]. For both measures, the acceptable minimum is 0.7 , which gives an approximation of both of these values [55] (p. 7). In order to obtain reliable results, it was decided to determine the confidence intervals of the studied factors. For this purpose, bootstrap analyzes were made, generating 2000 bootstrap samples with the size equal to the sample size $(n=304)$. In addition, the percentage of bootstrap tests in which the recommended minimum values of the analyzed measures were met ( 0.7 for Cronbach's alpha and CR) were given (Tables 3 and 4 ). 
Table 2. Descriptive statistics and indicator values for observable and latent variables.

\begin{tabular}{|c|c|c|c|c|c|c|c|c|}
\hline \multirow{2}{*}{ Latent Variable } & \multirow{2}{*}{ Observable Variable Measured on the Scale 1-5 } & \multirow{2}{*}{ Source } & \multicolumn{4}{|c|}{ Descriptive Statistics (Base) } & \multirow{2}{*}{$\begin{array}{l}\text { Cronbach's Alpha } \\
\text { CR, AVE }\end{array}$} & \multirow{2}{*}{ Factor Load } \\
\hline & & & Mean & Median & Trend & Standard Deviation & & \\
\hline \multirow{4}{*}{ Environmental turbulence } & Increase in change novelty & Ansoff [1] (p. 58) & 3.44 & 4 & 4 & 1.30 & \multirow{4}{*}{$\begin{array}{c}\alpha=0.8185 \\
\mathrm{CR}=0.824 \\
\mathrm{AVE}=0.541 \\
\text { Mean correlation between items: } 0.538\end{array}$} & 0.789 \\
\hline & Environment intensity increase & Ansoff ([1] (p. 58) & 3.98 & 4 & 4 & 1.08 & & 0.764 \\
\hline & Increase of environment change pace & Ansoff [1] (p. 58) & 4.00 & 4 & 4 & 1.02 & & 0.811 \\
\hline & Growing complexity of environment & Ansoff [1], (p. 58) & 3.71 & 4 & 4 & 1.19 & & 0.863 \\
\hline \multirow{3}{*}{ Reaction to change } & Company needs time to react to changes in the environment & Frishammar [10] & 4.62 & 5 & 5 & 0.75 & \multirow{3}{*}{$\begin{array}{c}\alpha=0.7886 \\
C R=0.796 \\
\mathrm{AVE}=0.663 \\
\text { Mean correlation between items: } 0.656\end{array}$} & \\
\hline & Company keeps up with the changes in the environment & Manu [18] (p. 123) & 3.68 & 4 & 4 & 1.22 & & 0.909 \\
\hline & Company reacts in advance to changes in the environment & Yoon, Lee., Yoon, Toulan [34] & 3.95 & 4 & 4 & 1.09 & & 0.909 \\
\hline \multirow{4}{*}{ Risk of collaboration } & Formalisation of collaboration & Todtling, Lehner, Kaufmann, [33] & 3.51 & 4 & 4 & 0.82 & \multirow{4}{*}{$\begin{aligned} & \alpha=0.65 \\
& 9 \mathrm{CR}=0.693 \\
& \mathrm{AVE}=0.433 \\
& \text { Mean correlation between items: } 0.393 \\
& 0.659 \\
& \mathrm{CR}=0.693 \\
& \mathrm{AVE}=0.433 \\
& \text { Mean correlation between items: } 0.393\end{aligned}$} & \\
\hline & Flexibility of parties & Fritsch [31] & 3.62 & 4 & 4 & 1.10 & & 0.761 \\
\hline & Awareness of risk & Światowiec-Szczepańska [19] & 3.39 & 4 & 4 & 1.01 & & 0.8131 \\
\hline & experience in collaboration & $\begin{array}{c}\text { Belussi [30], Nooteboom, Berger, } \\
\text { Noorderhaven [28], } \\
\text { Das, Teng [35], }\end{array}$ & 3.52 & 4 & 4 & 1.25 & & 0.7381 \\
\hline
\end{tabular}

Table 3. Bootstrap analyzes latent variable.

\begin{tabular}{|c|c|c|c|c|c|c|c|c|c|c|}
\hline \multirow{3}{*}{ Latent Variable } & \multicolumn{5}{|c|}{ Cronbach's Alpha } & \multicolumn{5}{|c|}{ CR } \\
\hline & \multirow{2}{*}{ Value } & \multirow{2}{*}{$\begin{array}{l}\text { Average from } \\
\text { the Sample }\end{array}$} & \multicolumn{2}{|c|}{$\mathbf{9 0} \%$ Bootstrap Confidence Interval } & \multirow{2}{*}{$\begin{array}{c}\text { Value }>0,7 \text { been } \\
\text { Achieved in: } \\
\text { [\% Samples] }\end{array}$} & \multirow{2}{*}{ Value } & \multirow{2}{*}{$\begin{array}{c}\text { Average from } \\
\text { the Sample }\end{array}$} & \multicolumn{2}{|c|}{ 90\% Bootstrap Confidence Interval } & \multirow{2}{*}{$\begin{array}{c}\text { Value }>0,7 \text { been } \\
\text { Achieved in: } \\
{[\% \text { Samples] }}\end{array}$} \\
\hline & & & LO & HI & & & & LO & HI & \\
\hline Environmental turbulence & 0.819 & 0.818 & 0.811 & 0.847 & $100.0 \%$ & 0.824 & 0.806 & 0.656 & 0.916 & $80.9 \%$ \\
\hline Reaction to changes & 0.789 & 0.790 & 0.759 & 0.819 & $100.0 \%$ & 0.796 & 0.794 & 0.742 & 0.868 & $100 \%$ \\
\hline Risk of collaboration & 0.659 & 0.702 & 0.637 & 0.765 & $66.6 \%$ & 0.693 & 0.674 & 0.577 & 0.817 & $65.6 \%$ \\
\hline
\end{tabular}

Table 4. Discriminant validity for particular constructs of the research model and their mutual correlations.

\begin{tabular}{|c|c|c|c|c|c|c|c|c|}
\hline & \multicolumn{5}{|c|}{ AVE } & \multirow{3}{*}{ Environmental Turbulence } & \multirow{3}{*}{ Reaction to Change } & \multirow{3}{*}{ Risk of Collaboration } \\
\hline & \multirow{2}{*}{ Value } & \multirow{2}{*}{$\begin{array}{l}\text { Average from the } \\
\text { Sample }\end{array}$} & \multicolumn{2}{|c|}{ 90\% Bootstrap Confidence Interval } & \multirow{2}{*}{$\begin{array}{c}\text { Value }>0,7 \text { been Achieved } \\
\text { in: }[\% \text { Samples }]\end{array}$} & & & \\
\hline & & & LO & HI & & & & \\
\hline Environmental turbulence & 0.541 & 0.554 & 0.495 & 0.605 & $91.66 \%$ & 0.735 & & \\
\hline Reaction to changes & 0.663 & 0.660 & 0.572 & 0.699 & $100 \%$ & $0.558^{* * *}$ & 0.814 & \\
\hline Risk of collaboration & 0.433 & 0.463 & 0.380 & 0.549 & $51.00 \%$ & 0.432 ** & 0.452 ** & 0.658 \\
\hline & & & & & & 3.781 & 4.086 & 3.553 \\
\hline Standard deviation & & & & & & 0.925 & 0.807 & 0.592 \\
\hline Skewness & & & & & & -0.755 & -0.903 & -0.455 \\
\hline Kurtosis & & & & & & 0.211 & -0.088 & -0.211 \\
\hline
\end{tabular}

Note: the square root value of AVE is shown on the diagonal, under the diagonal of the Pearson correlation coefficient. ${ }^{* * *}$ represents $p<0.001,{ }^{* *}$ represents $p<0.01$, and ${ }^{*}$ represents $p<0.05$. 
In the case of the risk of collaboration, the reliability improved significantly and over $65 \%$ of the samples obtained acceptable values (Table 3).

In turn, the accuracy was assessed on the basis of the following:

- Convergent validity, where AVE, whose value for each latent variable in the model should exceed 0.5 [60]. This condition is not met for risk of collaboration, because AVE is 0.433. Bootstrap analyzes (2000 bootstrap samples with the size 304 ) indicated that $51 \%$ of the samples obtained acceptable values (over 0.5); and

- Discriminant validity [60] (Table 4) to check the extent to which the identified latent variables are different from each other.

The square root AVEs are compared with the appropriate correlation factors. Their much higher values indicate a positive divergent validity test. Therefore, the individual latent variables differ significantly from one another.

In future research, it may be worthwhile to consider what observable variables should be added by conducting more in-depth desk research. Because of the theoretical conditions, it was decided that they would remain in the created model.

\subsection{Model Estimation}

This model is estimated using the maximum likelihood estimation, assuming a multidimensional normal distribution. Furthermore, no suspicious response pattern was observed, and also, following the outlier labeling rule, no significant outlier was observed; however the data was normal because no skewness or kurtosis statistics higher than one were found. In the case of the measurement and structural models, there is no reason to reject the hypothesis that the standardised residual values of the empirical and theoretical matrix are equal to zero $\left(\chi^{2}=53.568 ; p=0.000\right)$. The value of root mean square of approximation error $($ RMSEA $)=0.096($ RMSEALO $=0.075 ;$ RMSEAHI $=0.117)$ indicates a poor fit of the model. The values of $\chi^{2} / \mathrm{ss}=2.232$ indicate the acceptability of the model. Indices GFI $=0.936$ and AGFI $=0.898$ assume the values close to the required thresholds. All of the meters are on the limit of acceptability, so the model is poorly suited to the data, but can be used in the description.

\subsection{Results}

In the measurement model (Table 5), significant correlation dependencies are identified $(p<0.001)$ between the following:

- the assessment of the environmental turbulence and perception of the risk of collaboration with a force of 0.558;

- the assessment of environmental turbulence and assessment of reaction to change with a force of 0.632 ,

- the assessment of the reaction to change, and perception and collaboration risk with a force of 0.452 .

Table 5. Standardised values of estimated parameters in the measurement and structural model.

\begin{tabular}{|c|c|c|c|}
\hline \multicolumn{2}{|l|}{ Measurement Model } & \multicolumn{2}{|l|}{ Structural Model } \\
\hline Environmental turbulence $<->$ reaction to changes & $0.558^{* * *}$ & Environmental turbulence-> reaction to changes & $0.558^{* * *}$ \\
\hline reaction to changes $<->$ risk of collaboration & $0.452 * *$ & reaction to changes-> risk of collaboration & 0.144 \\
\hline
\end{tabular}

Note that with the increasing average perception of the turbulent environment and reactions to changes, the perception of risk of collaboration also, on average, increases.

On the basis of descriptive statistics, it is worth noting that the respondents most highly evaluate the average response to changes, then the uncertainty of the environment and evaluate the risk 
of cooperation the lowest. However, average values do not differ significantly from one another statistically. The greatest diversity is characterized by the uncertainty of the environment, then reaction to changes, and the lowest by the risk of collaboration (see Figure 2).

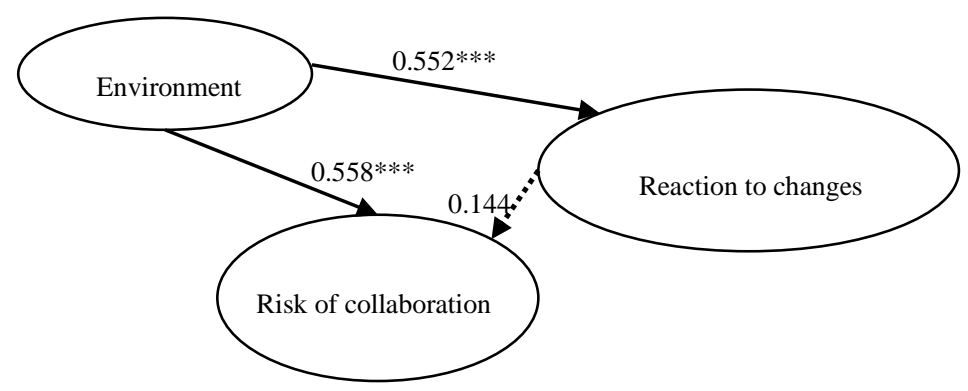

Figure 2. The empirical model of the influence of the environmental turbulence and reaction to change on the risk of collaboration with indicated standardised path indices. The arrows indicate the estimated standardised parameters. ${ }^{* * *}$ represents dependencies significant for $p<0.001$. The dashed line represents a statistically insignificant relationship.

The empirical data (Table 5, Figure 2) confirm that the perception of environmental turbulence has a significant and direct impact on the risk of collaboration and the company's reactions to change. However, it is not possible to confirm that the company's reaction to change has a statistically significant impact on the perception of the risk of collaboration. Therefore, a company's reaction to change does not mediate the impact of environmental turbulence on the risk of collaboration. In the respondents' perceptions, the higher the environmental turbulence, the higher the collaboration risk. Moreover, a higher-level perception of environmental turbulence affects the company faster and anticipates the company's reactions. There is a significant cause-effect relationship (see Table 5), as follows:

- with the risk of collaboration being impacted by the perception of turbulence- this is a positive direct effect on the level of 0.552 ; and

- with reactions to change being impacted by the perception of turbulence-this is a positive direct effect on the level of 0.558 .

\subsection{The Effect of a Moderating Variable}

At a later stage of research, it was tested whether the significance and force of this impact is identical in the groups distinguished in the sample, because of such characteristics as the size of the enterprise, the financial situation, and relationships with the cooperating parties.

The analyses carried out in groups with the provided characteristics (Table 6) show that in small and large companies, as well as in companies posting a profit or loss in 2016, the significance and force of impact in the presented model can be considered identical. However, the results indicate statistically significant differences in the case of companies defining relations with cooperating companies as only necessary or close. If the companies that define relationships as close or even partner-like, the impact of the reaction to change is significant and positive for the risk of collaboration, that is, if the company is capable of an on-going or anticipatory reaction to change, the risk of collaboration increases. Moreover, the impact force is statistically significantly different, namely:

- from environmental turbulence on the reaction to change-in the group of companies describing relationships as close, the force of this impact is significantly higher than in the group of companies where these relationships are only necessary;

- from environmental turbulence on the risk of collaboration-in the group of companies describing relations as close, the impact force is significantly lower than in the group of companies where these relationships are only necessary. 
Table 6. Standardised values of the estimated parameters in the structural model.

\begin{tabular}{|c|c|c|c|}
\hline Company Size in 2016 & Small $(n=231)$ & Medium $(n=73)$ & $p$-Value \\
\hline Environmental turbulence $\rightarrow$ reaction to change & $0.563^{* * *}$ & $0.525^{* * *}$ & 0.6934 \\
\hline Environmental turbulence $->$ risk of collaboration & $0.603^{* * *}$ & $0.462 * *$ & 0.1528 \\
\hline Reaction to change $\rightarrow$ risk of collaboration & 0.108 & 0.202 & 0.4811 \\
\hline Company financial standing in 2016 & Profit $(n=230)$ & Loss $(n=74)$ & $p$-Value \\
\hline Environmental turbulence $\rightarrow>$ reaction to change & $0.545^{* * *}$ & $0.610 * *$ & 0.4731 \\
\hline Environmental turbulence $\rightarrow>$ risk of collaboration & $0.541^{* * *}$ & $0.591 * *$ & 0.5886 \\
\hline Reaction to change $->$ risk of collaboration & 0.166 & 0.049 & 0.3841 \\
\hline Relation with cooperating party & Only necessary $(n=100)$ & Close $(n=204)$ & $p$-Value \\
\hline Environmental turbulence $\rightarrow$ reaction to change & $0.432 * *$ & $0.607^{* * *}$ & 0.0224 \\
\hline Environmental turbulence $\rightarrow$ collaboration risk & $0.769 * *$ & $0.474^{* * *}$ & 0.0000 \\
\hline Reaction to change $->$ collaboration risk & 0.084 & 0.210 * & 0.0148 \\
\hline
\end{tabular}

Therefore, in practical terms, this means that in the case of close relationships, environmental turbulence enforces a reaction to changes, and these increase the awareness of the risk of long-term collaboration. However, in the case of only the necessary relationships, the enterprises focus only on the current risk of collaboration. Consequently, in the case of companies maintaining close relationships with their parties, the reaction to change is a mediator of environmental turbulence to the risk of collaboration, as follows:

- the total impact of environmental turbulence on the risk of collaboration is 0.596 ;

- the direct impact of environmental turbulence on the risk of collaboration is 0.474 ; and

- the indirect impact of environmental turbulence on the risk of collaboration through reactions to change is $0.122(t=1.945, p=0.0247)$ [59].

Therefore, in the group of companies maintaining close relationships, the theoretical model is fully confirmed.

\subsection{Discussion}

The reactions to changes do not have a significant statistical impact on the risk of collaboration. This may be due to the low reliability of the latent construct risk of collaboration. The obtained results confirm the results presented in the literature, as follows:

- the assessment of environmental turbulence positively affects the perception of the risk of collaboration,

- the assessment of environmental turbulence positively affects the assessment of the reaction to changes, however,

- the significance of the impact of the reaction to the changes assessment on the risk of collaboration is not confirmed.

Based on the presented model, one observes that the reaction to change is the impact mediator in the group of companies maintaining close relationships with cooperating organisations. This means that the more entrepreneurs are aware of their flexibility, the higher the awareness of the risk of collaboration is. This is confirmed by the theses presented in the papers by McCarthy et al. [61] and Frishammar [10]. The results of the empirical research show the invariability of the impact of the perception of environmental turbulence on the risk of collaboration, depending upon the size of the company (as do the results obtained in 2016), which results from the growing awareness of managers, and which also confirms the considerations presented in the papers by McCarthy et al. [61], Manu [18], and Sull [12].

It is worth noting that the constructed risk of collaboration failed to include the observable variable of the formalisation of collaboration indicated in the papers by Todtling et al. [33] and Światowiec-Szczepańska [19]. An important element of the constructed risk of collaboration is as follows: 
(1) risk awareness, as indicated by Światowiec-Szczepańska [19];

(2) trust in a partner or experience in collaboration, indicated by Belussi's [30]; and the

(3) flexibility of parties, indicated by Fritsch's [31].

The empirical studies confirmed the conclusion of Belussi [30], that trust reinforces the awareness of the risk of collaboration, which is beneficial for both parties. Moreover, in the group of companies maintaining close relationships, it is shown, similarly to the conclusions by Frishammar [10], that the environment affects the functioning of the enterprise through its reactions to changes; that is, they adopt an adaptive attitude.

\section{Conclusions}

In the current era, risk management is becoming increasingly important. As part of empirical research, the regularity identified in theory is confirmed-environmental turbulence significantly affects the risk of collaboration, that is, in the surveyed companies with a greater awareness of changes taking place in the environment, came a greater awareness of the risk of collaboration.

Because of the use of structural modelling, it is possible to derive the cause and effect relationships between the identified constructs. The results invite further detailed considerations in the area of factors that identify the risk of collaboration. An important element of future research will be to identify the factors determining the use of the company's internal potential, or refocusing the search for opportunities on internal resources. In further research, it would be reasonable to expand this research with all of the observable variables identified in the literature that are part of the constructed risk of collaboration.

The paper is further motivated by interest in the role of technology in the development of transition economies. I study SMTEs in Poland, a country that has successfully transitioned to a free market economy, establishing a healthy entrepreneurial sector. Technological entrepreneurship is a new phenomenon that has not yet been explored in many areas, and I have wondered whether commonly known theories are applicable. It is widely agreed that the development of local networks can stimulate innovation, making the case for further research into the factors that affect collaboration.

The presented considerations are limited by the dataset, namely the opinions of the respondents, which are subjective by nature. What this means is that perception is measured through the prism of a respondent's subjective assessment. Moreover, limitations in the conceptual model being developed have resulted from the utilized critical analysis and the overview of the literature. Furthermore, a significant hindrance to the empirical research is the operationalization of the variables. A limitation to the applied structural modelling method is the circumstance where a good model fit does not prove the theory, but only makes it more probable. The model supports the validity of the causal model. However, it does not prove it, as it is only one of the potential explanations of the reality under study.

Funding: The research paper was funded by National Science Centre in Poland under the project 2014/13/B/HS4/01517 with the funds allocated to science in the years 2015-2017 as the research project.

Acknowledgments: This study was carried out under project 2014/13/B/HS4/01517, funded by the Polish National Science Centre.

Conflicts of Interest: The authors declare no conflict of interest.

\section{References}

1. Ansoff, H.I. Strategic Management; Palgrave Macmillan: Hampshire, UK. Available online: http:/ / dx.doi. org/10.1057/9780230590601 (accessed on 25 June 2017).

2. Schumpeter, J.A. The Theory of Economic Development; an Inquiry into Profits, Capital, Credit, Interest, and the Business Cycle; Harvard University Press: Cambridge, MA, USA, 1934.

3. Chen, E.; Katila, R.; McDonald, R.; Eisenhardt, K.M. Life in the Fast Lane: Origins of Competitive Interaction in News Established Markets. Strat. Manag. J. 2010, 31, 1527-1547. [CrossRef] 
4. Beckman, C.; Eisenhardt, K.; Kotha, S.; Meyer, A.; Rajagopolan, N. Technology entrepreneurship. Strat. Entrep. J. 2012, 6, 89-93. [CrossRef]

5. Baumol, W.J. Is There a U.S. Productivity Crisis? Science 1989, 243, 611-615. [CrossRef] [PubMed]

6. Zahra, S.A.; Sapienza, H.J.; Davidsson, P. Entrepreneurship and dynamic capabilities: A review, model and research agenda. J. Manag. Stud. 2006, 43, 917-955. [CrossRef]

7. Ferreira, J.J.; Ferreira, F.A.; Fernandes, C.I.; Jalali, M.S.; Raposo, M.L.; Marques, C.S. What do we [not] know about technology entrepreneurship research? Int. Entrep. Manag. J. 2016, 12, 713-733. [CrossRef]

8. Harms, R.; Walsh, S.T. An introduction to the field of technology entrepreneurship: Editorial to the special issue. Creat. Innov. Manag. 2015, 24, 552-557. [CrossRef]

9. Antoncic, B.; Prodan, I. Alliances, corporate technological entrepreneurship and firm performance: Testing a model on manufacturing firms. Technovation 2008, 28, 257-265. [CrossRef]

10. Frishammar, J. Organizational Environment Revisited. A Conceptual Review and Integration. Int. Stud. Manag. Organ. 2006, 36, 22-49. [CrossRef]

11. Kotler, P.; Caslione, J.A. Chaotics: The Business of Managing and Marketing in the Age of Turbulence; AMACOM: New York, NY, USA, 2009.

12. Sull, D. How to thrive in turbulent markets. Harv. Bus. Rev. 2009, 77, 78-88.

13. Eroglu, C.; Hofer, C. The Effect of Environmental Dynamism on Returns to Inventory Leanness. J. Oper. Manag. 2014, 32, 347-356. [CrossRef]

14. Dess, G.G.; Beard, D.W. Dimensions of Organizational Task Environments. Adm. Sci. Q. 1984, $29,52-73$. [CrossRef]

15. Lawrence, P.R.; Lorsch, J.W. Organization and Environment; Richard, D., Ed.; Irwin: Homewood, IL, USA, 1969.

16. Schneider, A.; Wickert, C.; Marti, E. Reducing Complexity by Creating Complexity: A Systems Theory Perspective on How Organizations Respond to Their Environments. J. Manag. Stud. 2017, 54, 182-208. [CrossRef]

17. Volberda, H.W.; van Bruggen, G.H. Environmental Turbulence: A Look into Its Dimensionality. In Dynamiek in Bedrijfsvoering; Bemelmans, M.T.A., Ed.; NOBO: Enschede, The Netherlands, 1997; pp. 137-145.

18. Manu, A. Value Creation and the Internet of Things, How the Behavior Economy Will Shape the 4th Industrial Revolution; Routledge: Abingdon, UK, 2015.

19. Światowiec-Szczepańska, J. Ryzyko Partnerstwa Strategicznego Przedsiębiorstw. Ujęcie Modelowe; Wydawnictwo Uniwersytetu Ekonomicznego: Wrocław, Poland, 2012.

20. Fudaliński, J. Risk Taking Propensity and Firm Internationalisation Process. Entrep. Bus. Econ. Rev. 2015, 3, 85-104. [CrossRef]

21. McMullen, J.S.; Shepherd, D.A. Entrepreneurial Action and the Role of Uncertainty in the Theory of the Entrepreneur. Acad. Manag. Rev. 2006, 31, 132-151. [CrossRef]

22. Alvarez, P.A.; Barney, J.B. Discovery and creation: Alternative theories of entrepreneurial action. Strat. Entrep. J. 2007, 1, 11-26. [CrossRef]

23. Porter, M.E. On Competition; Harvard Business School: Boston, MA, USA, 1998.

24. Golonka, M. Proactive cooperation with strangers: Enhancing complexity of the ICT firms' alliance portfolio and their innovativeness. Eur. Manag. J. 2015, 33, 168-178. [CrossRef]

25. Raco, M. Competition, collaboration and the new industrial districts: Examining the institutional turn in local economic development. Urban Stud. 1999, 36, 951-968. [CrossRef]

26. Ratajczak-Mrozek, M. Global Business Networks and Cooperation within Supply Chain as a Strategy for High-Tech Companies' Growth. J. Entrep. Manag. Innov. 2012, 8, 35-51. [CrossRef]

27. Short, J.C.; Ketchen, D.J.; Shook, C.H.L.; Ireland, R.D. The Concept of Opportunity in Entrepreneurship Research: Past Accomplishments and Future Challenges. J. Manag. 2010, 36, 40-65. [CrossRef]

28. Nooteboom, B.; Berger, H.; Noorderhaven, N.G. Effects of Trust and Governance on Relational Risk. Acad. Manag. J. 1997, 40, 308-338.

29. Dodgson, M.; Hinze, S. Measuring the innovation process. In Proceedings of the Conference on Data and Strategies in Evaluating Research and Development, Canberra, Australia, 15-16 November 1999.

30. Belussi, F. Local systems, industrial districts and institutional networks: Towards an evolutionary paradigm of industrial economics? Eur. Plan. Stud. 1996, 4, 5-26. [CrossRef]

31. Fritsch, M. Cooperation in Regional Innovation Systems. Reg. Stud. 2001, 35, 297-307. [CrossRef] 
32. Fritsch, M.; Franke, G. Innovation, Regional Knowledge Spillovers and RED; Working Paper 2000/25; Faculty of Economics and Business Administration, Technical University Bergakademie: Freiberg, Germany, 2000.

33. Todtling, F.; Lehner, P.; Kaufmann, A. Do Different Types of Innovation Rely on Specific Kinds of Knowledge Interactions? Institute of Regional Development and Environment. Vienna. 2008. Available online: http / / www.epub.wu.ac.at (accessed on 25 January 2018).

34. Yoon, C.; Lee, K.; Yoon, B.; Toulan, O. Typology and Success Factors of Collaboration for Sustainable Growth in the IT Service Industry. Sustainability 2017, 9, 2017. [CrossRef]

35. Das, T.K.; Teng, B.S. Trust, Control, and Risk in Strategic Alliances: An Integrated Framework. Organ. Stud. 2001, 22, 251-283. [CrossRef]

36. Anderson, J.C.; Gerbing, D.W. Assumption and comparative Strengths of the Two-Steps Approach. Sociol. Methods Res. 1992, 20, 321-333. [CrossRef]

37. Morgan, R.; Hunt, P. The commitment-trust theory of relationship marketing. J. Mark. 1994, 58, 20-38. [CrossRef]

38. Lush, R.F.; Brown, J.R. Interdependency, contracting, and relational behavior in marketing channels. J. Mark. 1996, 60, 19-38. [CrossRef]

39. Carson, S.J.; Madhok, A.; Wu, T. Uncertainty, Opportunism, and Governance: The Effects of Volatility and Ambiguity on Formal and Relational Contracting. Acad. Manag. J. 2008, 49, 1058-1077. [CrossRef]

40. Rašković, M.; Mörec, B. Determinants of supplier-buyer relationship competitiveness in transnational companies. Econ. Bus. Rev. 2013, 15, 5-31.

41. Rezazadeh, A.; Nobari, N. Antecedents and consequences of cooperative entrepreneurship: A conceptual model and empirical investigation. Int. Entrep. Manag. J. 2018, 14, 479-507. [CrossRef]

42. Anderson, P.W.; Christ, M.H.; Sedatole, K.L. Managing Strategic Alliance Risk: Survey Evidence of Control Practices in Collaborative Inter-Organizational Settings; The Institute of Internal Auditors Research Foundation: Lake Mary, FL, USA, 2006.

43. Westland, J.C. Lower bounds on sample size in structural equation modeling. Electron. Commer. Res. Appl. 2010, 9, 476-487. [CrossRef]

44. Meehl, P.; Waller, N. The Path Analysis Controversy: A New Statistical Approach to Strong Appraisal of Verisimilitude. Psychol. Methods 2002, 7, 283-300. [CrossRef] [PubMed]

45. Loehlin, J.C. Latent Variable Models: An Introduction to Factor, Path and Structural Equation Analysis; Lawrence Erlbaum: Mahwah, NJ, USA, 1987.

46. Anderson, J.C.; Narus, J.A. A Model of the Distributor's Perspective of Distributor-Manufacturer Working Relationships. J. Mark. 1984, 48, 62-74. [CrossRef]

47. MacCallum, R.; Wegener, D.; Uchino, B.; Fabrigar, L. The problem of equivalent models in applications of covariance structure analysis. Psychol. Bull. 1993, 114, 185-199. [CrossRef] [PubMed]

48. Mueller, R. Structural equation modeling: Back to basics. Struct. Equ. Model. 1997, 4, 353-369. [CrossRef]

49. Aaker, D.A.; Bogozzi, R.P. Unobservable variables in structural equation models with an application in industrial selling. J. Mark. Res. 1979, 16, 147-158. [CrossRef]

50. Jöreskog, K.G.; Sorbom, D. Advances in Factor Analysis and Structural Equation Models; Abt Books: Cambridge, MA, USA, 1979.

51. Hu, L.; Bentler, P.; Kano, Y. Can test statistics in covariance structure analysis be trusted? Psychol. Bull. 1992, 112, 351-362. [CrossRef] [PubMed]

52. Kline, R.B. Principles and Practice of Structural Equation Modeling; The Guilford Press: New York, NY, USA, 2005.

53. Schumacker, R.; Lomax, R. A Beginner's Guide to Structural Equation Modeling; Prentice Hall: Upper Saddle River, NJ, USA, 1996.

54. Pyka, A.; Kuppers, G. Innovation Networks: Theory and Practice; Edward Elgar Publishing Limited: Cheltenham, UK, 2002.

55. Hair, J.F.; Hult, G.T.M.; Ringle, C.M.; Sarstedt, M. A Primer on Partial Least Squares Structural Equation Modeling (PLS-SEM); Sage Publications: Los Angeles, CA, USA, 2014.

56. Nunnaly, J.C.; Bernstein, I.H. Psychometric Theory, 3rd ed.; McGraw-Hill: New York, NY, USA, 1994.

57. Kline, P. A Handbook of Test Construction; Methuen: London, UK, 1986.

58. Edwards, J.E.; Lambert, L.S. Methods for Integrating Moderation and Mediation: A General Analytical Framework Using Moderated Path Analysis. Psychol. Methods 2007, 12, 1-22. [CrossRef] [PubMed]

59. Fornell, C.; Larcker, D.F. Evaluating Structural Equation Models with Unobservable Variables and Measurement Error. J. Mark. Res. 1981, 18, 39-50. [CrossRef] 
60. Henseler, J.; Ringle, C.M.; Sarstedt, M. A New Criterion for Assessing Discriminant Validity in Variance-based Structural Equation modeling. J. Acad. Mark. Sci. 2014, 43, 115-135. [CrossRef]

61. McCarthy, I.P.; Lawrence, T.B.; Wixted, B.; Gordon, B.R. A Multidimensional Conceptualization of Environmental Velocity. Acad. Manag. Rev. 2010, 35, 604-626. 